\title{
Sütlü Tatlı Üretimi Yapan Bir İşletmede ISO 22000 Gıda Güvenliği Yönetim Sisteminin İncelenmesi
}

\author{
Burcu ÇEVIK*, Haydar ÖZPINAR ${ }^{* *}$
}

\section{$\ddot{O} \mathbf{z}$}

Amaç: Bu çalışmada çok sayıda şubeleri olan sütlü tatlı üreticisi büyük bir işletmede ürün girişinden tüketime sunulan süre içerisinde ISO 22000 gıda güvenliği yönetim sistemi standardının ne şekilde uygulandığı incelenmiştir.

Yöntem: Sütlü tatlı üretimi yapılan tesis, altı ay boyunca haftada üç kere ziyaret edilmiştir. Bu çalışma sırasındaki incelemeler, firmadaki kalite sorumlusu ile birlikte yapılmıştır. Görüşmeler; ISO 22000:2005 yönetim sisteminin standart maddelerinin soru-cevap şeklinde yorumlanması ile tamamlanmıştır.

Bulgular: Sütlü tatlı üretiminde kullanılan hammaddelerin tedarik edildiği firmalar onaylı tedarikçilerdir. Ambalaj özellikleri, araç durumu ve etiket bilgileri bütün hammaddeler için aynı olup ürün özelliklerinde farklı bulgular saptanmıştır. Firmada yapılan sütlü tatlı ürünlerinin kritik kontrol noktaları ve tehlike analizleri sırayla incelenmiştir. Üretim alanı gözlemlendiğinde, kritik kontrol noktalarına ve tehlike analizlerine uygun üretim yapıldı̆̆ı tespit edilmiştir. Sütlü tatlı yapım aşamasında iç malzeme yerleştirme esnasında, eldivenin yırtılması sonucunda personel kaynaklı fiziksel tehlike tespit edilmiştir. Tutulan eğitim kayıtlarında temizlik ve hijyen kurallarına uyulması konusunda personele tekrar eğitim verildiği saptanmıştır.

Sonuç: Sütlü tatlı üretimi yapan işletmede, hammadde kabul kriterlerinin belirlenmiş ve akış şemalarının oluşturulmuş olduğu, risk değerlendirmesinin yapılmış olduğu ve kritik kontrol noktalarının (fiziksel, kimyasal, mikrobiyolojik) tespit edilerek kayıt altına alındığı saptanmıştır.

\section{Özgün Araştırma Makalesi (Original Research Article)}

Geliş / Received: 04.03.2019 \& Kabul / Accepted: 29.03.2019

${ }^{*}$ Yüksek Lisans Öğrencisi, İstanbul Aydın Üniversitesi, Fen Bilimleri Enstitüsü, Gıda Güvenliği

Ana Bilim Dalı, İstanbul, Türkiye, E-posta: burcucevik@stu.aydin.edu.tr

ORCID ID https://orcid.org/0000-0003-4242-0989

** Prof. Dr., İstanbul Ayvansaray Üniversitesi, Fen Bilimleri Enstitüsü, İstanbul, Türkiye, E-posta: haydarozpinar@ayvansaray.edu.tr ORCID ID https://orcid.org/o0oo-0003-38469907 
Anahtar Sözcükler: ISO 22000, besin işleme, kritik kontrol, potansiyel tehlike.

\title{
Investigation of the ISO 22000 Food Safety Management System in Milk Puddings Production Company
}

\begin{abstract}
Aim: In this study, it has been examined how the ISO2200o Food Safety Management System Standard is applied in a large enterprise producing milk puddings with many branches, within a time period from the product entrance to consumption.

Method: The facility where milk puddings was produced was visited three times a week for six months. The investigations during this study were carried out together with the people who are responsible for quality in the company. Interviews were completed with question and answer by interpreting the standard items of the ISO22000:2005 Management System.

Findings: The companies in which the raw materials used in the production of milk puddings are supplied are approved suppliers. Packaging properties, vehicle condition and, label information are the same for all raw materials and different findings have been found in product properties. Critical control points and hazard analyzes of the milk puddings products which are produced in the company were examined respectively. When the production area is observed, it has been determined that production is performed according to critical control points and hazard analyzes. As a result of glove rupture, physical hazards arising from personnel have been identified in the internal material placement process shown during the milk puddings construction phase. It has been determined that training is provided to the personnel again in order to comply with the rules of cleanliness and hygiene as per the training record.

Conclusion: It was determined that the raw material acceptance criteria were determined and flow charts were established, the risk assessment was made and critical control points (physical, chemical, microbiological) were determined and recorded in the enterprise that makes the production of milk puddings.
\end{abstract}

Keywords: ISO22000, food prossesing, critical control, potential hazard.

\section{Giriş}

Süt insan beslenmesinde çok önemli bir yere sahiptir. Sütün bu üstün besin niteliğinden daha çok yararlanmak amacıyla dayanıklılık süresini uzatmak, tüketici sağlığını korumak ve değişik nitelikli ürünler elde etmek için çeşitli süt ürünleri üretim 
teknolojileri geliştirilmiştir. Bunlardan en fazla tüketileni ve tercih edileni sütlü tatlilardir ${ }^{1}$.

Sütlü tatlıların "güvenli gıda” olarak tüketiciye sunulması gereklidir. Güvenli gıda; insan tüketiminde herhangi bir hastalığa yol açacak tehlikelerin olmaması, fiziksel, kimyasal ve mikrobiyolojik özellikleri itibariyle insan tüketimine uygun olan, sağlık bakımından herhangi bir tehlike barındırmayan ve besin değerini koruyan gıda maddesi olarak adlandırılmaktadır ${ }^{2}$. Ülkeler kendi ulusal standartlarını geliştirmişlerdir33. Gıda güvenliğinin sağlanması bütün gıda işletmeleri için günümüzdeki en önemli konudur. Gıda güvenliği tehlikelerinin tarif edilmesi ve kontrol ettiğinin ispatlanması gıda işletmeleri tarafından yapılmalıdır. Küresel olarak kabul gören gıda güvenliği standartlarını tatbik ederek bu şartları sağladıklarını göstermelidir. ISO 22000 en son Eylül 2005’te gıda güvenliği ile ilgili standardı yayımlamıştır. ISO 22000 içeriği ise; firma tarafında üretilen gıda ürününün, bandın en başı olan hammadde kabulünden, çatalın ucunda bulunan tüketiciye ulaşana kadar olan tüm gıda güvenliği sürecin gözlem ve kontrol altına alarak tehlikeleri henüz oluşmadan önlemeyi hedefler. Bununla birlikte herhangi bir hastalık riskini tüketicilerden uzak tutarak, bu riskten etkilenmelerini önler².

Sütlü tatlılar; yapısında süt olması nedeniyle hızla mikrobiyolojik bozulma riski taşımaktadır. $\mathrm{Bu}$ nedenle sütlü tatlı üreten işletmelerde gıda güvenliği kurallarının özenle uygulanması gereklidir. Ülkemizde süt ve diğer hammaddeler için belirlenen spesifikasyonlarda ürünlerin yeterince bulunamaması, üretimde çalışan personelin eğitim kalitesinin yetersizliği ve hizmet içi eğitim sürekliliğinin sağlanamaması, iç ve dış denetimlerin yetersizliği gibi sorunlar nedeniyle, sütlü tatlı üretimi yapan işletmeler için ISO 22000 gıda güvenliği yönetim sisteminin kurulması ve uygulanması oldukça önem arz etmektedir.

Bu çalışmada; sütlü tatlı üretimi yapan bir tesiste, ISO 22000 gıda güvenliği yönetim sisteminin uygulanıp uygulanmadı̆̆ının yerinde gözlemlenmesi ve kalite dokümanlarının incelenmesi amaçlanmıştır.

\section{Gereç ve Yöntem}

ISO 22000 gıda güvenliği yönetim sistemi, İstanbul'un Levent ilçesinde bulunan sütlü tatlı üretimi yapan bir firma üzerinde uygulanmıştır. Firma $3600 \mathrm{~m}^{2}$ 'lik bir alana 
sahiptir. Firma 400 L/gün süt işlemektedir. Firmada kazandibi, fıstıklı muhallebi, meyveli muhallebi, tavukgöğsü ve sütlaç yapılmaktadır. Firmada fabrika müdürlüğüne bağlı olmak üzere sütlü tatlı üretiminden sorumlu 1 üretim müdürü (kalite sorumlusu) ve altında 17 kişi çalışmaktadır. İşletmeye her gün, 250 L Manda 150 L İnek sütü olmak üzere 400 L süt gelmektedir. İşletmenin Kırklareli’nde kendi sahip olduğu mandıradan gelen sütler sabah saat 5'de sağıldığ gibi $+4^{\circ} \mathrm{C}$ 'deki frigolu araçlarla soğuk zincir kırılmadan sabah saat 8'de İstanbul Levent'teki imalathaneye getirilmektedir. İşletme ayrıca İstanbul Beykoz'daki bir çiftlikten her gün $10 \mathrm{~kg}$ tavuk göğüs fileto almaktadır. Diğer katkı maddeleri olan $300 \mathrm{~kg}$ şeker, $10 \mathrm{~kg}$ tuz, $30 \mathrm{~kg}$ Antep fistığı, $30 \mathrm{~kg}$ vişne, 500 kg sübyelik pirinç üretim gereği olan aylık ihtiyaç kadarı anlaşmalı tedarikçilerden kalite standartlarına uygunluğunu belirten raporların sonucuna göre alınmaktadır.

Ambalaj olarak aylık 3000 adet tek kullanımlık 200g kapasiteli porselen kâse gelmektedir.

Sütlü tatlılar 6 ayda 1 kalaylanan 5o L hacimli bakır kazanlarda ve paslanmaz çelik karıştırıcı kepçeler kullanılarak geleneksel yöntemlerle hazırlanmaktadır.

Sütlü tatlı üretimi yapılan tesis, altı ay boyunca haftada üç kere ziyaret edilmiştir. Bu çalışma sırasındaki incelemeler, firmadaki kalite sorumlusu ile birlikte yapılmıştır. Görüşmeler; ISO 22000:2005 yönetim sisteminin standart maddelerinin, soru-cevap şeklinde yorumlanması ile tamamlanmıştır. Firma tarafından oluşturulan hammadde spesifikasyonları, ürün tanımları, proses akış şemaları ve belirlenen kritik kontrol noktaları ile potansiyel tehlikeler detaylıca incelenmiştir.

\section{Bulgular}

Sütlü tatlı üretiminde kullanılan hammaddelerin tedarik edildiği firmalar onaylı tedarikçilerdir. Tedarikçi denetimleri yılda bir kez kalite sorumlusu tarafından yapılmıştır. Denetim sırasında tespit edilen bulgular ve faaliyet raporları kayıt altına alınmıştır. Ambalaj özellikleri, araç durumu ve etiket bilgileri bütün hammaddeler için aynı olup ürün özelliklerinde farklı bulgular saptanmıştır.

Sütlü tatlı üretiminde ana hammaddeler olarak; süt, fıstık, vişne, tuz, pirinç, toz şeker ve tavuk kullanılmıştır. $\mathrm{Bu}$ hammaddelerin ambalaj özellikleri ve etiket bilgileri incelenmiştir. Ürünlerde sevk süresince hasar görmeyecek malzeme kullanılmıştır. Ürünün yapısını etkilemeyecek malzemeden yapılmıştır. Yırtık, delik saptanmamıştır. 
Etikette üretici firmanın ticari unvanı ve açık adresi, ürünün açık adı, cinsi, net ve brüt ağırlı̆̆ı, ürün özellikleri-içeriği ve muhafaza koşulları, Türk Gıda Kodeksi’ne uygun üretildiği yazısı, üretim ve son kullanma tarihleri yazılmıştır. Etiket bilgileri okunaklı ve düzgündür.

Araçta birbirini etkileyen ürünler saptanmamıştır. Araç kasasının temiz ve kapalı olduğu görülmüştür.

Sütte pH 6,60-6,70; yăg ise \%3,00-3,50 değerlerinde bulunmuştur. Kuru madde oranı 8,50-9,50 bx aralığındadır. Kendine has renk ve kokusu vardır. Yanık, acı, ekşi, tuzlu, metalimsi, pişmiş veya hoş sayılmayan okside tat saptanmamıştır.

Toz şekerde yabancı madde saptanmamıştır. Rafine, 1. kalite ve yerli şeker alınmaktadır. Üründe kurtlanma saptanmamıştır. Üründe küf saptanmamıştır. Her ürün kendine has koku, tat ve renktedir.

Antep fistığında yabancı madde, kurtlanma ve küf saptanmamıştır. Her ürün kendine has koku, tat ve renktedir. Tedarikçiden temin edilen iç Antep fıstığı satın alma Şartnamesi doğrultusunda kontrol edilmiştir ve \%10 oranında kabuk içerdiği tespit edilmiştir. Şartnamede belirtilen kriterlere uygun olmadığı için, uygun olmayan ürün raporu düzenlenmiş ve tedarikçiye iade edilmiştir.

Pirinç kendine has tat ve kokudadır ve gözle görülür küflü tane, böcek ve böcek parçaları ile kalıntıları, hayvansal atık ve kalıntıları saptanmamıştır. Rutubet miktarı en fazla \%14,5'dur. Kırık tane oranı \%5’ten fazla değildir. Yarım ve yarımdan küçük kırık pirinç taneleri \%7’e kadar kabulü sağlanmıştır. Bozuk, lekeli, tane, çöp, kabuk ve çeltikli tane \%1’i geçmemektedir. Camsı ve mat görünümdedir.

Tuz, depolanma sırasında topaklaşmaya neden olmayacak iyi bir granülasyona sahiptir. Fiziksel olarak temiz, parlak ve beyazdır. Topaklaşmaya neden olabilecek higroskobik safsızlıklar saptanmamıştır. Suda çözünürlüğü yüksektir. Hamurda ve üründe yă̆ oksidasyonu ve ransiditeyi hızlandıran $\mathrm{Cu}$ ve $\mathrm{Fe}$ mineralleri saptanmamıştır.

Vişnede kurtlanma, küf saptanmamıştır. Vişne büyüklükleri standart büyüklükte, irilikte ve olgunluktadır (minimum $1 \mathrm{~cm}$ çapında). Her ürün kendine has koku, tat ve renktedir. 
40-42 günlük ithal ve don tavuk etleri kabul edilmiştir. Veteriner sağlık raporu her parti için alınmıştır. Derisi tüylerinden iyice temizlenmiş şekildedir. Baş, boyun, ayaklar, kursak, kuyruk, kuyruk üstü yağ guddesi, solunum borusu, iç yağlar, bağırsak, yutak, böbrek, döllenme organları, akciğerleri, karaciğer, taşlığı vb. iç organlarından tamamen temizlenmiştir. Gelen et yüzeyinde lekelenme, morarma, beneklenme, çürük, ekşi koku, tüy diplerinde tam veya yarı belirgin kan lekeleri saptanmamıştır. Etler usulüne uygun kesilip temizlenmiş, insan besini olarak tüketime engel bir durumda olmayıp günlük kesimdir. Gelen tavuk etleri çok zayıf, iyi gelişmemiş veya kaşektik (yeterli gelişme gösterememiş) değildir. Derisinde anormal derecede koyu renk saptanmamıştır.

Şirketin gıda güvenliği ile ilgili dokümanları incelenmiş, çalışan personele şirketin gıda güvenliği politikası ile ilgili sorular yöneltilmiş ve sonuç olarak şirket yönetiminin, politikaların tanımlamasını yaptığı, yazılı hale getirdiği ve firmada anlaşılmasını sağladığı tespit edilmiştir. Üretim ve ofis alanlarında gıda güvenliği politikası ile ilgili bilgilendirme afişlerinin bulunduğu görülmüştür.

İncelenen toplantı tutanakları ile firmanın üst yönetiminin, yönetim kurulu başkanı başkanlığında, belirli aralıklarla (yılda en az 1 kez) yönetimi gözden geçirme toplantısı yaptığı saptanmıştır.

Üretilecek ürüne özgü reçeteye göre, kalite standartlarına uygun hammadde ile üretim yapılırken; kalite sistemlerinin gerektirdiği hijyenik koşulların sağlandı̆̆ı, üretimde eğitimli, sağlık kontrolleri yapılmış personel kullanıldığı ve aseptik koşullarda dolum yapılarak kalite standartlarına uygun ürün elde edildiği görülmüştür. Bu tespitler için, üretimde çalışan personelin hijyen belgelerinin kayıtları ve eğitim kayıtları incelenmiş, hammaddeler içinse, hammadde sertifikaları kontrol edilmiştir.

Temizlik kayıtları incelenerek, işe başlamadan önce üretim alanının tüm bölümlerinin temizlik planları doğrultusunda temizlendiği görülmüştür. Üretimde hijyenik kaliteyi sağlamak amacıyla bölümlerin ve ekipmanların temizlik işlemleri temizlik planlarına göre yapılmıştır. Temizlik planlarına göre yapılan temizlik işlemlerinin kontrol kayıtları her bölüm için kontrol formu kullanılarak tutulmaktadır. Üretimde kontrollerin sürekliliğini sağlayabilmek için hijyen denetimlerinin ayda bir, personelin kişisel hijyen 
kurallarına uyumunu kontrol amacı ile personel hijyen denetimlerinin her gün yapıldığı, denetim kayıt formları ile saptanmıştır.

İşletmenin, dış pest kontrolü için anlaşmalı Pest kontrol firması kemirgenlere yönelik yerleştirilen yemli istasyonların bakımını yapıldı̆̆ı görülmüştür.

Anlaşma koşullarına göre ayda bir kez veya 15 günde bir bakımları yapılmakta ve buna dair ilaçlama raporları, HACCP kaydı olarak belirtilen sürelerde saklandığı tespit edilmiştir.

Üretim personeli işe alınmadan önce bulaşıcı enfeksiyon içermediğini (verem, zatürre gibi üst solunum yolları enfeksiyonu, hepatit b) kanıtlayan akciğer filmini de içeren bir sağlık raporu ile kayıt altına alındığı görülmüştür. Tutulan eğitim kayıtları incelendiğinde personelin temizlik ve dezenfeksiyon işlemlerinde kullanılması gerekli deterjan ve dezenfektanlar konusunda belirli aralıklarla eğitim aldığı tespit edilmiştir. Personel üretim sahasında çalışırken firmanın kurum kimliğine göre giyindiği gözlemlenmiştir.

Depo ve üretim alanlarının sıcaklık takiplerinin kayıt formları ile yapıldığı, üretim alanı için uygun kıyafetlerin giyildiğinin kontrolü ve üretimde yasak olan davranışların (üretim alanında takı takmak, yemek yemek gibi) kontrolü için kalite sorumlusu tarafından günlük denetimler yapıldı̆̆g tespit edilmiştir. Acil durumlar için olaya müdahale edecek personel listesi bulunduğu görülmüştür.

Hazırlanan ürünler sevk edilmeden önce kontrol edilmekte ve son kontrol raporu ile kayıt altına alındığı görülmüştür. İncelenen son kontrol raporunda ürünün görsel kontrolünün (ambalaj ve etiket kontrolü), ürünün fiziksel özelliklerinin uygunluğunun (renk, koku ve tat) ve üründe yabancı madde kontrolünün yapıldığı tespit edilmiştir. İncelenen 5 çeşit sütlü tatlı için uygulanan testler aynı olup görsel kontrolleri için belirlenen spesifikasyonlar ürün içeriğine göre farklılık göstermiştir.

İncelenen kayıtlarda, denetçilerin ISO 22000 standartları konusunda bilgili, iç denetim eğitimi almış, denetleme ve sorgulama yeteneğine sahip personel arasından seçildiği görülmüştür. Denetçi seçiminin yönetim temsilcisi tarafından yapıldığı ve genel müdürün onayı alındığı, her bölümün denetçisi o bölüm dışında olan bağımsız personel arasından seçildiği saptanmıştır. 
Üretilen her ürün, kalite sorumlusu tarafından kontrol edildiği ve onaylandıktan sonra sevk edildiği görülmüşsür. Kalite sorumlusu tarafından sevkiyat öncesinde; ürünün ambalajının doğruluğunu, etiket üzerindeki üretim ve son kullanma tarihleri ile içerik bilgilerini görsel olarak kontrol edildiği ve görsel kontrollerden sonra; üretim sırasında fiziksel kontroller yapılmış olmasına rağmen sevkiyat öncesinde ambalajlanan ürünlerin her tepsisinden üçer adet olmak üzere numune alınarak; renk, koku ve tat kontrolleri yapıldığı tespit edilmiştir. İncelenen kayıtlarda, üretim ve sevkiyat sırasında yapılan çift kontrol sonrasında uygun bulunan ürünler son kontrol raporu ile gıdayla uygun sevkiyat aracına yüklendiği ve kalite sorumlusu, ürünleri belirlenen spesifikasyonlara uygun bulmadığı takdirde son kontrol raporunu onaylamadığı ve sevkiyatına izin vermediği saptanmıştır. Uygun olmayan ürünler için inceleme, kalite sorumlusu tarafından başlatıldığı görülmüştür.

İncelenen kayıtlarda izlenebilirlik, üretim tarihi ve parti numarası, girdi kontrol ve sevkiyat kontrol formları ile sağlandığı görülmüsştür. Uygun olmayan ürünlerin, hizmet formu ile kayıt altına alındığı ve düzeltici faaliyetlerin başlatıldığı görülmüştür.

Müşteri şikâyetleri ve önerilerinin formlar ile takip edildiği ve kayıt altına alındığı görülmüştür. Kayıt altına alınan formlar incelendiğinde, müşteri şikâyeti ile ilgili düzeltici faaliyetin başlatıldığı tespit edilmiştir. Düzeltici faaliyetin en kısa zamanda prosedürüne uygun sonuçlandırıldığı görülmüştür. Şikâyete konu olan hususun firma kusuru mu yoksa firmanın kontrolü dışında olan bir sebepten mi kaynaklandığ edilmiştir. Her iki durumda da müşteriye bilgi verildiği saptanmıştır. Şikâyet giderilip düzeltici faaliyet kapatıldıktan sonra müşteriye bilgi verildiği görülmüştür.

Isı gerekli cihazların kullanılarak kontrol edildiği ve ısı kontrol formu ile kayıt altına alındığı görülmüştür. Ölçüm cihazlarının kalibrasyon işlemleri, izleme ve ölçme cihazları kontrolü prosedürüne göre yapıldı̆̆ı tespit edilmiştir. İncelenen kayıtlarda, ölçme ve izleme cihazları için yıllık kalibrasyon planı yapıldığı görülmüş ve kalibrasyonu yapılacak tüm cihazların yılda en az bir kez kalibre edildiği saptanmıştır. İncelenen kayıtlarda, kalibrasyon sonuçlarının değerlendirildiği görülmüştür. Firmada yapılan sütlü tatlı ürünlerinin akış şemaları sırayla incelenmiş ve üretim yerinde takip edilerek akış şemasına uygun üretim yapıldığı gözlenmiştir. Firmada yapılan sütlü tatlı ürünlerinin kritik kontrol noktaları ve tehlike analizleri sırayla incelenmiştir. Üretim alanı gözlemlendiğinde, kritik kontrol noktalarına ve tehlike analizlerine uygun üretim 
yapıldığı tespit edilmiştir. Ancak; sütlü tatlı yapımında iç malzeme yerleştirme esnasında, eldivenin yırtılması sonucunda, personel kaynaklı fiziksel tehlike tespit edilmiştir. Tutulan eğitim kayıtlarında temizlik ve hijyen kurallarına uyulması konusunda personele tekrar eğitim verildiği saptanmıştır.

\section{Tartışma}

Türkiye'de, son zamanlarda birçok sektörün yanı sıra gıda sektöründe de kalite yönetim sistemi kurulması ve uygulanmasına yönelik olumlu gelişmeler olduğu gözlenmektedir. Bu çalışmada sütlü tatlı üretimi yapan bir işletmede TS EN ISO 22000 gıda güvenliği yönetim sisteminin incelenmesi amaçlanmıştır.

Sütlü tatlı ürünleri, etkin yeterlilikte ısıl işlemine tabii tutulan ürünler olmasına rağmen üretimden sonraki aşamalarda gerekli hijyenik önlemlerin alınmaması durumunda yani; personelin hijyen talimatlarına uymaması sonucu yabancı madde bulaşması (toz, kir, saç, kıl), makine-ekipmanların yeterli durulama sağlanamaması sonucunda olabilecek kimyasal bulaşma, depo sıcaklık kontrollerinin yapılmaması sonucunda sıcaklığın yükselmesi ile birlikte ortaya çıkabilecek mikrobiyolojik bulaşma nedeniyle insan sağlığı için potansiyel bir risk olabilmektedir. Temiz ve güvenilir gıda üretimi için kalite yönetim sisteminin uygulanması önemlidir.

Sütlü tatlı üretiminin ana hammaddesi olan çiğ sütün hızlı mikrobiyolojik bozulma riski, istenen kalitede hammadde temininde sıkıntı, çalışan personelin eğitim kalitesinin düşüklüğü ve eğitim devamlılığının sağlanamaması, küçük işletmeler nedeniyle oluşan haksız rekabet koşulları ve denetim yetersizliği nedeniyle iyileştirmenin sağlanamaması gibi sebeplerden ötürü gıda güvenliği yönetim sistemine ihtiyaç duyulmaktadır. İşletmelerde ISO 22000 gıda güvenliği yönetim sisteminin etkin bir şekilde uygulanması; ürün kalitesinin geliştirilmesini, marka güvenilirliğinin ve müşteri memnuniyetinin arttırılmasını, ürün kayıplarının ve müşteri şikâyetlerinin azaltılmasını, üretim ve kalite kontrol maliyetlerinin azaltılmasını, gıda zehirlenmesi risklerinin azaltılmasını ve pazarda rekabet üstünlüğü sağlamaktadır.

Müşteri memnuniyeti ya da marka kaygısı olmayan merdiven altı olarak da tabir edilebilen küçük işletmelerin, sütlü tatlı üretimi yapan işletmelerin yaklaşık \%70’ini oluşturduğu düşünülmektedir. Bu işletmelerde yetersiz ısıl işlem, eğitimsiz personel ve kalite uygunluğu olmayan hammadde ile hijyenik olmayan koşullarda üretim 
yapılmaktadır. Fakat bu çalışmada incelenen şirket gibi olan büyük şirketler; marka bilinirliği ve piyasadaki itibarı sebebiyle, müşterilerine karşı her yönden kaliteyi sağlayacağını taahhüt etmektedir. Bir işletmede gıda güvenliği yönetim sisteminin kurulması maliyetli olduğu için de küçük işletmeler tarafından göz ardı edilmektedir.

Gıda işletmelerinde denetimlerle gıda güvenliği sağlanabilmektedir. Amerikan Gıda ve İlaç Dairesi (Food and Drug Administration (FDA)) gıda kurumu gıda kaynaklı oluşabilecek her türlü tehlikelerin önüne geçilmesi amacıyla gıda firmalarının yılda iki kez denetlenmesini tavsiye etmektedir. Denetimlerin verimli olduğu tartışılmaktadır ${ }^{4}$. Küçük işletmelerde özellikle hijyen konusunda yaşanan kalite sorununun önüne denetimlerle geçilebileceği düşünülmektedir. $\mathrm{Bu}$ çalışmada incelenen işletmenin denetim raporlarına bakıldığında düzeltici faaliyetlerin verimli bir şekilde gerçekleştirildiği ve denetimlerin verimli olduğu gözlenmiştir. Bu çalışmada incelenen işletmede hammadde kabul kriterlerinin belirlendiği, kontrol ve kayıtlarının standart gerekliliklerine uygun yürütüldüğü görülmüştür. Ancak; örneğin, hammadde kriterlerine uygun olmayan kabuk oranında Antep fistığının işletmeye gönderildiği görülmüş ve kayıtlar incelendiğinde bu durumun birkaç kez tekrar edildiği tespit edilmiştir. Firmanın tedarikçi denetimlerinde eksiklikleri olduğu saptanmıştır. İç denetim bulguları incelendiğinde ise; bulguların çoğunun personel kaynaklı hatalar olduğu görülmüştür. Personel eğitimleri konusunda eksiklikler olduğu ve eğitimlerin sıklaştırılması gerektiği düşünülmektedir. İşletmede hammadde kabulü ve sevkiyat aşamasına kadar tüm fiziksel, biyolojik ve kimyasal tehlikeler belirlenmiş ve uygulanarak kayıt altına alınmıştır. Bu süreçte işletmede müşteri memnuniyeti ve tüketici sağlığının korunması bilinci bulunmaktadır. Bu bilinç tüketicinin işletmeyi farklı bir şekilde algılamasına ve bu sayede günümüzde mevcut olan rekabet ortamında bir farklılık yarattı̆̆ı gözlenmektedir.

Bu konuda; 2012 yılında İzmir'de ISO 22000 gıda güvenliği yönetim sistemi standartlarının uygulanabilirliğini analiz etmek amacıyla çalışma yapılmıştır. ISO 22000 gıda güvenliği yönetim sistemi belgesine sahip 8 yiyecek içecek işletmesinin kalite ve hijyen sorumluları ile görüşmeler yapılmış ve elde edilen veriler, içerik analiz yöntemi ile analiz edilmiştir. Araştırma sonucunda, işletmelerin ISO 22000 gıda güvenliği yönetim sistemi uygulanması konusunda yaşadıkları sorunlarda çözüme yönelik çalışma olarak gerekli kaynakları yaratarak (depolar, mutfak alan vb.) ihtiyaç 
duyulan yapının kurulması halinde bu sistemin uygulanabilirliğinin arttı̆̆ görülmüştür. Bu çalışma, ISO 22000 sisteminin kurulumundaki zaafları gösterdiği için önemli bir çalışmadır ${ }^{5}$. İncelenen işletmede de kalite sürekliliğini sağlamak için sürekli iyileştirme yaklaşımı ile gerekli kaynakların oluşturulmaya çalışıldığı görülmüştür. Yine İzmir de 2003 yılında yapılan bir çalışmada, gıda sektöründe HACCP ve ISO 9001:2000 kalite yönetim sistemi ilişkisi incelenmiştir. Bu çalışmaya göre HACCP ile ISO kalite sistemlerinin bütünleşmesinin toplam kalite yönetimine ulaşmada büyük etki ve yararı olduğu görülmüştür. Bu şekilde sistemlerden birinin gerekliliklerinin toplam performans açısından eksik kaldığı noktada diğeri bu açı̆̆ı kapatacak uygulamaları ortaya koyacaktır. Aynı şekilde HACCP sisteminin de tek başına uygulanması gıda güvenliğini garanti altına almasına karşın, beklenen kalite düzeyinin


ISO 22000 gıda güvenliği sisteminin incelenmesi konusunda Türkiye'de yapılmış bir araştırma yoktur. Sistemlerin iyileştirilmesi, geliştirilmesi, izlenebilirliği ve gerektiğinde geriye çă̆ırma prosesinin sağlanması için kalite kayıtlarının etkinliği ve güncelliği de oldukça önemlidir. Asıl hedef; her zaman en üst düzeyde gerekliliklerin yerine getirilmesi ve rekabet ortamında farklılık yaratmadır.

\section{Sonuç}

Sütlü tatlı üretimi yapan bir işletmede ISO 22000 gıda güvenliği yönetim sistemi incelenmiş ve firmanın bu sistemi tüm proseslerine entegre ederek uygulamaya çalıştığı, standardın şartlarını fiilen yerine getirdiği ancak iyileştirmesi gereken yönleri (tedarikçi denetimleri ve eğitimler) olduğu görülmüştür. Üst yönetimin ve çalışan personelin standarda yönelik uygulamaları benimsediği ve bunun firmanın kalite yönetimi ve gıda güvenliğinin sağlanması için artı değer sağladı̆̆ı tespit edilmiştir.

\section{KAYNAKLAR}

1. Alli I. Quality System Standarts, Food Quality Assurance: Principles and Practices. Washington: CRC Pres.; 2004. 
2. Binkley M, Nelson D, Almanza B. Impact of manager certification on food safety knowledge and restaurant health inspection scores in Tippecanoe County, Indiana. Journal of Culinary Science and Technology. 2008;6(4):343-350. doi: 10.1080/15428050802523925.

3. Bucak T. Yiyecek İçecek İşletmelerinde ISO 22000 Gıda Güvenliği Yönetim Sisteminin Uygulanabilirliği: İzmir İli Örneği. [doktora tezi]. İzmir, Türkiye: Dokuz Eylül Üniversitesi Sosyal Bilimler Enstitüsü; 2012.

4. Karaali A. Gıda İşletmelerinde HACCP Uygulamalar ve Denetimi. Ankara: T. C. Sağlık Bakanlığı Temel Sağlık Hizmetleri Genel Müdürlüğü; 2003.

5. Tekinsen C. Süt Ürünleri Teknolojisi. Konya: Selçuk Üniversitesi Veterinerlik Fakültesi; 2000.

6. Topoyan M. Gıda Sektöründe Kritik Kontrol Noktaları ve Tehlike Analizleri (HACCP) ve ISO 9001:2000 Kalite Yönetim Sistemi İlişkisinin İncelenmesi. [yüksek lisans tezi]. İzmir, Türkiye: T.C. Dokuz Eylül Üniversitesi Sosyal Bilimler Enstitüsü; 2003. 